\title{
Alpine skiing injuries
}

\author{
Y. Sahlin, MD
}

Trondheim Regional and University Hospital, Norway

\begin{abstract}
Alpine skiing accidents admitted to the Trondheim Regional and University Hospital during one year were recorded. Of the 339 injured, 67 per cent were male and 33 per cent were female. Eighty-seven per cent were outpatients, and 13 per cent were hospitalized. Falling accidents (67 per cent), followed by collision accidents ( 17 per cent), were the most common cause of injury. The injuries in the lower extremities were caused by falling and the head injuries were mostly casued by collisions.

Knee ligament strains were the most common injuries, and 17 per cent of these were hospitalized and required operative treatment. Of the minor knee strains, all 44 per cent were not fully recovered after two and a half years.

Seventeen patients sustained tibial fractures, eleven of them spiral fractures and six transverse fractures. The patients with spiral fractures were younger than the patients with transverse fractures. Head injuries were the most severe injuries, with eleven concussions and two epidural haematomas.
\end{abstract}

Keywords: Accident registration, alpine skiing injuries, knee ligament strains, head injuries in childhood, preventive measures

\section{Introduction}

Alpine skiing is an increasingly popular activity in mid Norway. During the last decade, a number of new ski resorts have opened in this area.

A number of studies of skiing accidents have been carried out over the years, most of them with the object of reducing injuries to the lower extremities. Improvement in bindings and ski boots have reduced the number of tibial fractures and minor knee strains ${ }^{1-4}$. However, severe ligament tears of the knee and severe head injuries are still unresolved problems. A study of fatal accidents among skiers in Vermont shows that 16 out of 18 fatally injured skiers died due to head injuries ${ }^{5}$.

Skiing accidents in different areas of the world do not follow the same pattern of injury ${ }^{1,6-9}$. Consequently, there is a need for local accident studies with the object of finding useful preventive measures to reduce the number and severity of the injuries due to alpine skiing.

The goal of this study was to provide the epidemiological information on alpine skiing acci-

Address for correspondence: Dr Y. Sahlin, Emergency Clinic, Trondheim Regional and University Hospital, Trondheim, Norway

(C) 1989 Butterworth \& Co (Publishers) Ltd

0306-3674/89/040241-04\$03.00 dents in mid Norway, and so discover useful preventive measures to reduce the number and severity of injuries.

\section{Material and methods}

All patients admitted to Trondheim Regional and University Hospital as a result of an accident during the period June 1985 to June 1986 were recorded. This is the only hospital in the Trondheim area. It is the local district hospital with a primary care uptake of about 200000 inhabitants and serves as a county and regional hospital for 610000 inhabitants. The data in this study are therefore a total registration of skiing injuries in the region. Both hospitalized as well as outpatients were included.

Each patient was identified as one case even if more than one injury was diagnosed. Information on each patient, including when, where and how the accident occurred, time of admission to the hospital, the body part injured, the diagnoses, severity of the injury, treatment, number of consultations and number of days in the hospital were collected and analysed.

For the collection of data, all patients filled out a questionnaire at their first attendance at the hospital. This information was combined with that from the hospital record. A further questionnaire was sent out to the 52 patients with minor knee strains treated as outpatients two and a half years after the injury. This included questions such as whether the patient was fully recovered after his or her injury, and if so, the length of time the disability persisted.

An accident was defined as a sudden external occurrence leading to a personal injury and requiring medical care. The injuries included in this study were less than one month old at the first attendance at the hospital. For grading the severity of the injury the AISscore (The Abbreviated Injury Scale, The American Association for Automobile Medicine, 1976) was used. The chi-square test and the student t-test (two-tail) were used for statistical analysis. P-values below 0.05 were regarded as significant.

\section{Results}

Details of 339 patients were recorded. The mean age of the injured was 21 years old (median $20 \mathrm{yr}$, range 5-62 yr). Sixty-seven per cent were male and 33 per cent were female (Figure 1). 


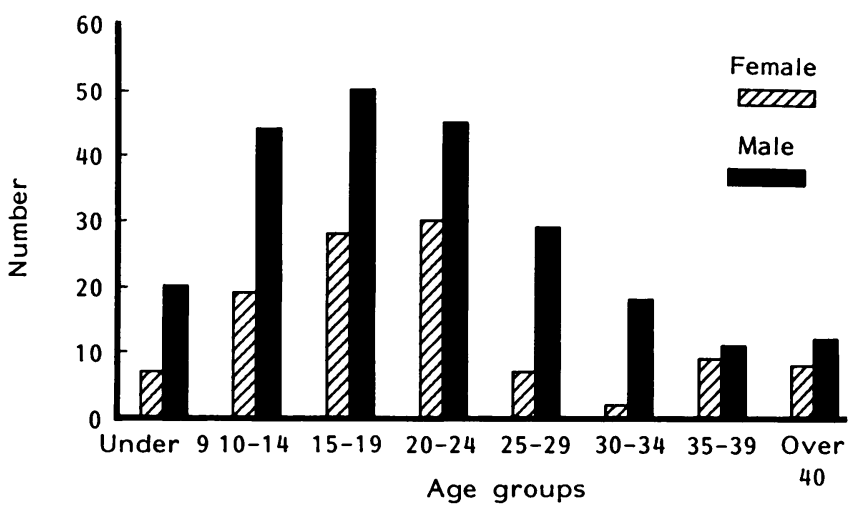

Figure 1. Distribution of age and gender of the alpine skiing injured patients, $n=339$

The winter season in mid Norway is long, so skiing accidents occurred from November to May with few accidents during the summer time. There were no differences in the causal mechanisms, diagnosis or severity of the injuries between those injured early and late in the skiing season.

Eighty-seven per cent (295) were treated as outpatients and 13 per cent (44) were hospitalized. The mean number of consultations for the outpatients were 1.7 (median 1, range 1-11), with a total of 501 consultations. The hospitalized patients spent an average of 6.1 days (median 4, range 1-48), in hospital, giving a total of 268 days. Seventy-three per cent of the injuries were minor injuries, and none of the accidents was fatal (Figure 2). There were no differences in severity based on sex or age.

Falling was the cause of 67 per cent of the accidents, while 17 per cent were due to collisions with objects or other persons. The falling accidents significantly more often caused injuries of the extremities, and the collision accidents significantly more often caused head injuries (Table 1).

Knee ligament strain was the most common finding and occurred in 62 injuries (Table 2). Ten patients with knee ligament strains required hospitalization and operative treatment; five had anterior cruciate ligament tears and five had medial collateral ligament tears. The 52 knee injuries treated as outpatients required an average of two consultations (range 1-10).

The questionnaire sent out to the 52 patients two and a half years after the injury was answered by 30 patients (58 per cent). Twenty-seven per cent said that they were fully restored within one month after the accident, 20 per cent were restored within four months, and the other 53 per cent required more than four

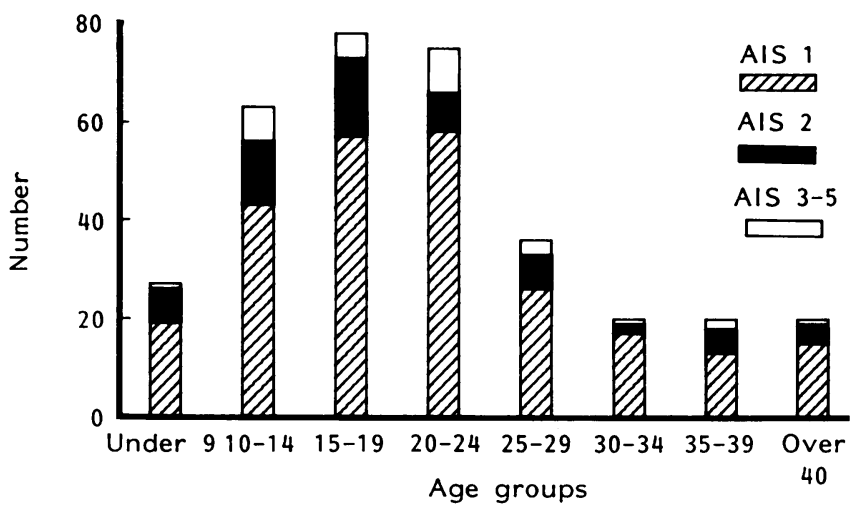

Figure 2. Distribution of injury severity score (AIS) in the different age groups in alpine skiing injured patients, $n=339$

months for recovery. Forty-seven per cent were still not fully recovered after their knee injury and either had pain, reduced mobility or the injury had led to reduced sport activity.

There were 17 patients with tibial fractures. Eleven fractures were of the spiral type and six were transverse, so called 'boot top' fractures. The patients with spiral fractures were significantly younger $(p<0.05$, mean 12, range 5-35) than the 'boot top' fractures (mean 19, range 13-40). None of the tibial fractures required operative treatment, but eight of these patients required hospitalization so that the fractures could be reduced under general anesthesia. The other nine were treated with a plaster cast as outpatients.

The head and neck injuries (14 per cent of all injuries) were significantly more severe according to AIS than injuries of other body parts $(p<0.05)$. Thirtythree per cent of the patients with head and neck injuries had injuries more severe than AIS 2. Eleven were diagnosed as concussion and two were treated for epidural haematoma with evacuation of the haematomas immediately after arrival at the hospital. One of the patients with epidural haemotoma is permanently disabled with reduced brain function. The mean age of the patients with severe head and neck injuries (AIS > 2) was $19 \mathrm{yr}$ (range 8-41 yr, median 17 $\mathrm{yr}$ ). There was no difference in the mean age between the patients with severe head injuries and the injured skiers as a whole.

\section{Discussion}

The mean age in our study is lower than in a study by Johnson and Ettlinger ${ }^{1}$. Both Blitzer et al. ${ }^{6}$ as well as

Table 1. Site injured and mechanism of injury

\begin{tabular}{|c|c|c|c|c|c|}
\hline Injury site & Fall & Collision & Other & & otal \\
\hline $\begin{array}{l}\text { Lower limb } \\
\text { Upper limb } \\
\text { Head/neck } \\
\text { Trunk } \\
\text { Multiple sites }\end{array}$ & $\begin{array}{r}121 \\
105 \\
20 \\
21 \\
5\end{array}$ & $\begin{array}{r}15 \\
13 \\
24 \\
6 \\
-\end{array}$ & $\begin{array}{l}1 \\
3 \\
4 \\
0 \\
-\end{array}$ & $\begin{array}{r}137 \\
121 \\
48 \\
27 \\
5\end{array}$ & $\begin{array}{r}40 \% \\
36 \% \\
14 \% \\
8 \% \\
2 \%\end{array}$ \\
\hline Total & 273 & 58 & 8 & 339 & $100 \%$ \\
\hline
\end{tabular}


Table 2. Distribution of injuries

\begin{tabular}{lrr}
\hline \multicolumn{1}{c}{ Diagnoses } & Number & Percent \\
\hline Knee strain & 62 & 17.6 \\
Sprain in the upper extremities & 47 & 13.5 \\
Contusion of lower extremities & 35 & 10.2 \\
Contusion in the upper extremities & 26 & 7.5 \\
Contusion of trunk & 25 & 7.2 \\
Forearm/hand fracture & 23 & 6.6 \\
Tibial fracture & 17 & 4.9 \\
Laceration, upper extremities & 16 & 4.6 \\
Rib/scapula/clavicle fracture & 13 & 3.7 \\
Concussion & 11 & 3.2 \\
Contusion of head/face & 11 & 3.2 \\
Humerus fracture & 7 & 2.0 \\
Fibula/malleolar fracture & 7 & 2.0 \\
Laceration, head/face & 4 & 1.2 \\
Head/face fracture & 3 & 0.9 \\
Shoulder dislocation & 3 & 0.9 \\
Columna fracture & 2 & 0.6 \\
Femur fracture & 2 & 0.6 \\
Intra-cranial haematomas & 2 & 0.6 \\
Other & 31 & 9.0 \\
\hline Total & 347 & 100 \\
\hline
\end{tabular}

Table 3. Distribution of type of injury

\begin{tabular}{lcr}
\hline Type of injury & Number & Percent \\
\hline Strain & 136 & 39 \\
Contusion & 113 & 32 \\
Fracture & 75 & 22 \\
Laceration & 23 & 7 \\
\hline Total & 347 & 100 \\
\hline
\end{tabular}

Moreland ${ }^{7}$ found that approximately 20 per cent of accidents occurred in children under 16 years old. In this study, as well as in other Scandinavian studies, 38 per cent of the accidents occur in children younger than 16 years ${ }^{x, 10,11}$. This suggests that the proportion of younger injured skiers is higher in Scandinavia than in America. This also reflects the fact that, in this study as well as in other Scandinavian studies, there are more injuries to the lower than to the upper part of the body compared with similar American studies.

The present gender distribution is also found in similar studies ${ }^{1,3}$. Johnson and Ettlinger state that female skiers are more predisposed to minor knee strains'. It is not therefore surprising that the proportion of minor knee ligament strains is similar in this present study as in that by Johnson and Ettlinger.

The mechanisms of accidents is similar to that found by Forster and Strohmenger in their study ${ }^{2}$. Older studies show a lower percentage of collision accidents ${ }^{2}$. The increasing number of collision accidents might be due to higher speeds and an increase in numbers of skiers on the slope ${ }^{3,12}$. Forster and Strohmenger noticed that higher speed among skiers have led to a new type of skiing injury, namely multiple trauma injuries similar to those suffered by motorcyclists ${ }^{2}$. In our study we did not see this kind of injury.

The problem of how to reduce the number of severe knee ligament strains has not been resolved by either this or other ski accident studies. This should be an im- portant priority for the ski boot and binding designers. Ettlinger and Johnson state in their study on equipment related injuries that currently used bindings only prevent the tibial injuries and not the severe knee injuries ${ }^{13}$.

The follow-up questionnaire shows that the majority of the so-called minor knee strains had a long restitution time. The fact that 47 per cent of the injured were not fully restored suggests that there could be a large number of overlooked ligament tears. There is a need for further biomechanical investigations of this group of patients. A Norwegian study of 150 consecutive anterior ligament tears showed alpine accidents to be the main cause for this injury ${ }^{14}$.

The Johnson et al. study finds that the risk of tibial fracture is four times higher in the child than in a adult'. In our study, the percentage of tibial fractures in those under 19 years old is 2.8 times higher than for adults.

Johnson and Ettlinger, Suckert et al. and Ungerholm et al. found a higher percentage of bending fractures compared with twisting fractures ${ }^{1,10,12}$. In our study, the spiral fractures which are due to twisting are 1.2 times as common as transverse fractures due to bending. This is supported by earlier studies ${ }^{1,2,15}$. The fact that we found a higher percentage of tibial fractures in the young explains the difference in distribution of twisting and bending fractures compared with the American study.

Ekeland showed that Norwegian skiers do not service their equipment as often as Swedish skiers ${ }^{16}$. One of ten children in an American study have badly fitted equipment". The tibia of a child is relatively weaker and will fracture with less bending and twisting than the tibia of an adult ${ }^{13}$ and therefore the child requires better adjusted equipment to prevent such injuries. The mean age of the patients with spiral fractures is much lower than the mean age of the patients with transverse fractures. In other countries such as USA and Sweden, the importance of having equipment perfectly adjusted, especially among children has been emphasized. This has been carried out through the increased use of a testing device both in the ski shop and at the ski areas ${ }^{10}$. This should be adopted in Norway and could reduce the number of tibial fractures.

An Australian report shows that one fifth of all severe head injuries are due to skiing accidents ${ }^{1-}$. The percentage of severe head injuries in this study is about the same as in similar studies ${ }^{6,9}$. Too little attention has been paid to these severe injuries. They might be prevented by the use of protective head gear ${ }^{5,11,18}$. In this country, a helmet is required for alpine practice and competition for children below the age of 13 . There is no basis in the literature, including this present study, for an upper age limit of 13 years for mandatory helmet use. Blitzer et al. found a higher incidence of head injuries in skiers under 17 years old, with the highest incidence in children betwen 13 and 17 years old $^{6,-0}$. Ungerholm et al. reported the same finding in their study, with no statistical difference between the mean age in the group with head injuries and the rest of the injured skiers'. Better control by the skiers, lower speeds and a better awareness of the surroundings could also reduce the incidence of severe head injuries' . 
The injury pattern in alpine skiing requires good first aid organization at the ski areas. The severe head injuries, the eventual multi-trauma patients, and the fractures of long bones require immediate medical assistance. As the two patients with epidural haematomas in this report demonstrated, organization of fast and safe transport to a hospital for further treatment is necessary.

\section{Acknowledgement}

Thanks to Professor Inggard Lereim and to Dr Lars Engebretsen for helpful suggestions. This study was supported by grants from Sør-Trøndelag county.

\section{References}

1 Johnson, R.J. and Ettlinger, C.F. Alpine ski injuries: Changes through the years Clin Sports Med 1982, 1, 181-197

2 Forster, H. and Stohmenger, U. Das geandrerte Bild des Skiunfalles Aktuel Traumatol 1984, 14, 1-4

3 Locke, L. Alpine skiing-injuries and prevention Aust Fam Physician 1987, 6, 793-795

4 Lorentzon, R., Persson, O. and Bjørnstig, U. Utforsåkningsskador dyra for samhallet Tibiafraktur kostar 8 200 kronor Lakartidningen 1986, 11, 960-962

5 Morrow, P., Eleanor, N., McQuillen, N., Eaton, L. and Bernstein, C. Downhillski fatalities: The Vermont experience J Trauma 1988, 1, 95-100

6 Blitzer, C., Johnson, R., Ettlinger, C. and Aggeborn, K. Downhill skiing injuries in children Am I Sports Med 1984, 2, 142-147
7 Moreland, M. Skiing injuries in children Clin Sports Med 1982, 2, 241-251

8 Daljord, O.A. and Maelum, S. Alpinskader i Oslo Tidskr Nor Laegeforen 1986, 17-18, 1482-1484

9 Ungerholm, S., Engkvist, J., Gierup, V. and Lindsjø Balkfors, B. Skiing injuries in children and adults: a comparative study from an 8-vear period Int I Sports Med 1983, 4, 236-240

10 Ungerholm, S, and Gustavson, J. Skiing safety in children: A prospective study of downhill skiing injuries and their relation to the skier and his equipment Int $I$ Sport Med 1985, 6, 353-358

11 Nygren, A., Tingvall, C. and Gustavsson, $H$. Epidemiology of head injuries in Sweden Acta Neurochir 1986, 36, 10-12

12 Suckert, K., Genelin, A. and Hørbst, W. 25 Jahre alpiner Schisport Aktuel Traumatol 1986, 16, 213-220

13 Ettlinger, $C$. and Johnson, $R$. The state of the art in preventing equipment-related alpine injuries Clin Sports Med 1982, 2, 199-207

14 Engebretsen, L., Fasting, O., Mølster, A., Strand, T. and Benum, P. Treatment of acute ruptures of the anterior cruciate ligament. A prospective randomized study on three surgical techniques Proceedings from 44nd meeting Scan Orthop Society, Århus, 1988

15 Freeman, J., Weawer, J., Oden, R. and Kirk, R. Changing patterns in tibia fractures resulting from skiing Clin Orthop 1987, 216, 19-23

16 Ekeland, A. Skiskader bland nordmenn og svensker Tidskr Nor Laegeforen 1983, 25, 1741-1743

17 Lehman, L.B. Neurologic injuries from wintersporting accidents Postgrad Med 1986, 8, 96-98

18 Oh, S. and Schmid, D. Kindliche Kopfverletzungen beim Skifahren und ihre optimale Prophylaxe Z Kinderchir 1983, 38, 66-72 